\title{
A Distance-learning Course on Indoor Environmental Comfort in Buildings
}

\author{
https://doi.org/10.3991/ijim.v11i5.7075 \\ Manuel Gameiro da Silva $\left.{ }^{\circledR}\right)$, Luísa Dias Pereira, João A. Dias Carrilho, Joana Neto, \\ Maria José Marcelino, Mário Mateus, Nelson Silva Brito, Sandra Pedrosa \\ University of Coimbra, Portugal \\ manuel.gameiro@dem.uc.pt
}

\begin{abstract}
A project for the creation and implementation of a distancelearning course on Indoor Environmental Comfort in Buildings (IECB) is presented. This course resulted from a request by Ordem dos Engenheiros (Portuguese engineering professional body) to the University of Coimbra. It was based on the Indoor Environmental Quality (IEQ) course of the Master in Energy for Sustainability and $\mathrm{PhD}$ in Sustainable Energy Systems of the University of Coimbra, coordinated by the first author. Jointly with the support of the Distance Education Service of the University of Coimbra, using as a starting point the existing contents of a formal discipline, the teaching methodologies and a set of activities were developed to implement a distance-learning course with a strong e-learning component by the students. Diversified strategies, using the existing platform running on Moodle, such as webinars, virtual laboratories, remote access labs, discussion forums and synchronous sessions, were tested to ensure a dynamic and interested engagement of the students along the course.
\end{abstract}

Keywords-E-learning course, Indoor Environmental Comfort in Buildings, Moodle, Virtual labs

\section{Introduction}

The Indoor Environmental Comfort in Buildings (IECB) course was developed as a partnership project between the Energy, Environment and Comfort research group of ADAI-LAETA, from the Mechanical Engineering Department of the University of Coimbra (UC) and the Distance-learning service of the same university. Its creation resulted from an invitation to UC by Ordem dos Engenheiros (Portuguese engineering professional body), for making available a course in this area through a distancelearning platform.

As there was already a regular discipline on Indoor Environmental Quality (IEQ), integrated in the educational programme of the Master in Energy for Sustainability and $\mathrm{PhD}$ in Sustainable Energy Systems of the University of Coimbra [1], [2], this was used as starting point for the structuring of the distance-learning course on IECB. Previous experience of the first author in the coordination of a manual published by REHVA (Federation of European Heating, Ventilation and Air Conditioning Associa- 
tions) [3], in the areas of Thermal Environment and Indoor Air Quality (IAQ), was also an important factor in the decision to bring forward this project.

The course main objectives were:

- Giving the trainees the theory knowledge and practical training on the subjects related to environmental comfort in buildings;

- Developing the trainees' capacities to define the indoor environment project conditions and to assess these in existing buildings.

These general guidelines entail the skills to be developed by the students, as follows:

1. Acknowledging the technical aspects and regulations related to the various areas of analysis of IEQ;

2. Integrating the information on various relevant partial aspects for environmental quality indoors (thermal environment, indoor air quality, noise, vibration, lighting);

3. Diagnosing the IEQ proposing improvement measures;

4. Integrating the knowledge related to IEQ in professional activities related to design, construction, installation, operation, licensing, and maintenance of buildings and systems;

5. Acting as agents of knowledge dissemination related to the course, including raising awareness of the need for harmonizing concerns regarding IEQ with the requirement of rational use of energy.

The main methodologies used for transfer of knowledge, to ensure the communication between the various players and to guarantee the assessment processes are presented in the current paper.

\section{Organization and Functioning of the Course}

The course on Indoor Environmental Comfort in Buildings (IECB) [4] is structured in five modules, subdivided into twenty-three themes. The introductory Module (0) frames the trainees into the course and promotes their training in the use of a computer platform [5]. The following modules (1-4) have a technical character, covering topics related to Thermal Environment (1), Indoor Air Quality (2), Noise and Vibration (3) and Lighting (4), as presented in Figure 1. 
UNIVERSIDADE DE COIMBRA

ENSIND A DISTÂNCIA

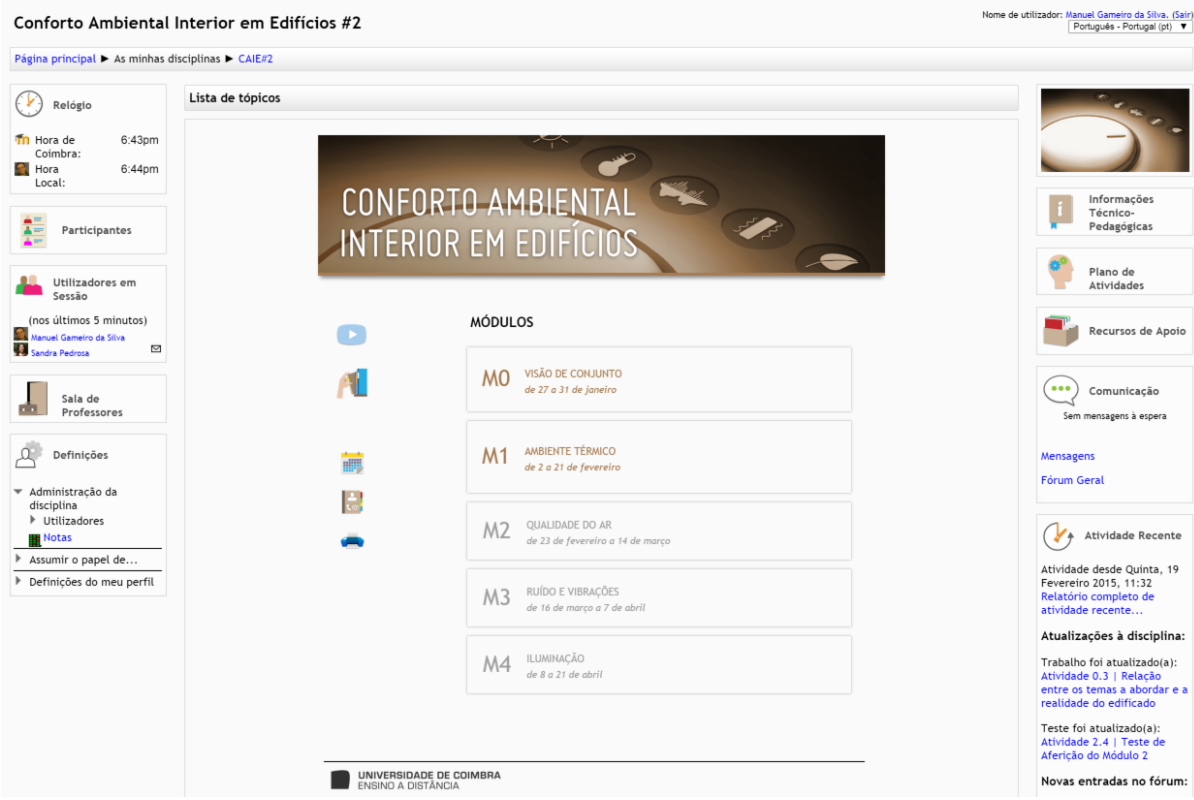

Fig. 1. Graphical interface of one of the access pages to the IECB course platform

The course is designed for a total of 81 hours of work corresponding to 3 ECTS (European Credit Transfer and Accumulation System) credits, according to the following plan:

Module 0 | Overall view (10 hours)

Theme 0.1 | the student in virtual learning environments

Theme $0.2 \mid$ objectives and modules of the course

Theme 0.3 | comprehensive overview

Module 1 | Thermal environment (20h)

Theme 1.1 | thermal comfort concept and mechanisms of heat and mass transfer

Theme 1.2 thermal balance of the human body

Theme 1.3 thermoregulation of the body

Theme 1.4 thermal comfort indices

Theme 1.5 | thermal comfort assessment

Theme 1.6 | thermal comfort adaptive model

Module 2 | Indoor air quality (20h)

Theme 2.1 | fundamentals

Theme 2.2 | ventilation elements

Theme 2.3 IAQ instrumentation

Theme $2.4 \mid$ analysis methodologies

Theme 2.5 | IAQ audits

Module 3 | Noise and vibrations (20h)

Theme 3.1 | fundamentals 
Theme 3.2 | generation and propagation of sound fields

Theme 3.3 | urban noise - acoustic environment

Theme 3.4 | acoustic quality in buildings

Theme 3.5 | occupational vibrations

Module 4 | Lighting (11h)

Theme 4.1 | systems of units and quantities

Theme 4.2 | fundamentals

Theme 4.3 | functioning of the human vision

Theme 4.4 | visual environment testing.

The course modular organization allows specific content, activities and assessment in each module. Each module has its own timeframe, with beginning and closing dates. This is a sequential modular structure, dependent of the realization of the proposed activities in agreement with the general schedule of the course. The course program is presented in the Appendix.

The course is entirely at distance, supported by a Moodle platform, not requiring in-person sessions. Moodle, acronym of Modular Object-Oriented Dynamic Learning was developed by Martin Dougianas as a software package for internet based disciplines, having been designed to support a social and constructive approach of teaching, in which the teacher role is to give answers to the students learning needs.

Along the course, the learning tasks were conceived to allow exploring various cognitive domains, in a progression that, normally, obeyed an ordering type: knowledge, understanding, implementation, analysis and synthesis. Not all the modules in the course have involved the same cognitive domains, but it can be stated that the three first were always present and that, from the last two, at least one of them was explored.

Moodle includes a group of basic functionalities:

1. Reserved access and different user profiles - each participant has its own private area and particular role in the course (student, teacher, manager, administrator or visitor).

2. Managing the access to contents - contents can be placed online in different formats, moments and in different forms of interaction with the students.

3. Synchronous and asynchronous communication tools.

4. Registration and controlling systems of the activities - automatic reports of the activities of the platform.

In addition, Moodle enables the definition of activities of diverse character, such as forums, chats, glossaries, surveys, tests, wikis, workshops, works, etc. that enable the application of different teaching methodologies. The access to the platform is flexible, allowing the students to organize and adequate their working schedule in function of the proposed activities. The interactions between the students and the teaching team are established mostly asynchronously, not requiring the simultaneous presence of the different counterparts in the platform. The existence of synchronous sessions is however expected (with participants communicating online at the same time), through an 
online communication tool, in a date/time to be defined during the period of the course.

The evaluation process used in the course is based on the continuous evaluation model, made from the execution of specific activities - the student progression to the following module is only allowed in case he/she has completed the proposed activities in the precedent module. A period of improvement of the performed activities is foreseen in each module, in which the student may reformulate his works. All the activities may be subject to improvement, during the corresponding improvement period, excepting the assessment test of each module, which can be done only once. The number of activities that can be improved in each module is defined according to the formula $\mathrm{n}-1$ ( $\mathrm{n}=$ number of activities of the module).

Module 0 has a diagnosis and formation character, and it is not considered in the final evaluation of the student. Nevertheless, all the activities within this module are mandatory and the failure to carry out these activities compromises the student progression and engagement in the course. The final grade corresponds to the arithmetic average of the grades obtained by the students in the various assessment activities along the course (test, practical exercises and reports), being assigned in a 0-20 scale.

\section{Teaching/Learning methods}

The teaching-learning process is based on the appropriation of the contents and support material provided on the platform for the study of the subjects, and on the systematic follow up of the individual and collective work of the students. An active and collaborative work methodology is developed, in which the students build up competences in the framework of the general thematic of the course, through the diverse activities that are proposed.

The concern of defining the learning tasks in function of the cognitive domains that were intended to be worked was present during the IECB course plan elaboration, as described in [5]. The first contact of the students with the subjects is done through access to the contents developed by the teaching staff in the form of slide presentations and original documents, included in the platform by the UC distance learning unit team. These are consistently organized with the study plan of the course and are selected by the students through the theme index. This learning task corresponds to the acquisition of basic knowledge (information acquisition and remembering). In Figure 2, for example, the platform graphical interface is presented, showing contents of Module 1.

Student learning is complemented with support from reading, visioning and exploring the resources available in each module. Support resources include webinars, created by the teaching staff, in which are orally explained some slide presentations or image sequences generated from virtual labs. There are also some videos produced by the UC television team, in which the teachers explain the use of some measuring devices used in the framework of the various modules of the course. Books, scientific articles, norms and internet websites of scientific communities and enterprises related to the topics of the course are also provided by the platform. 
UNIVERSIDADE DE COIMBRA

ENSINO A DISTÂNCIA

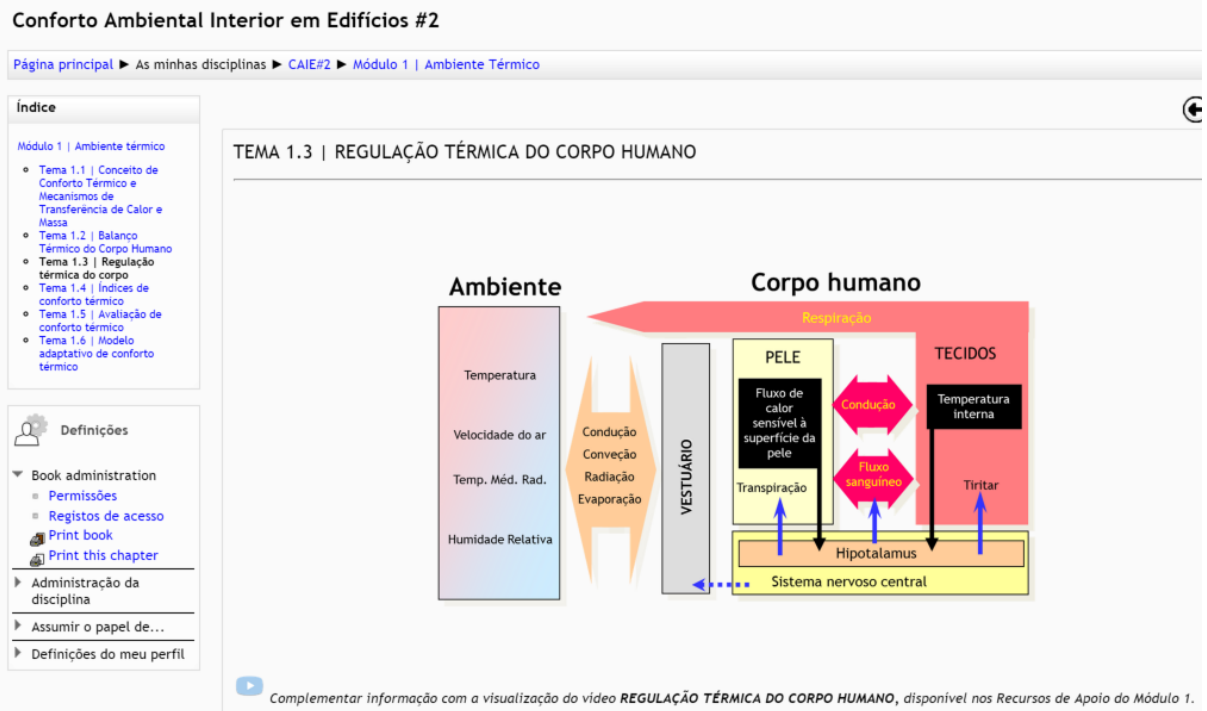

Fig. 2. Graphical interface of one of the content pages of the IECB course

At this stage, it may be considered that the cognitive domain of subject understanding is being worked; it is expected that the students establish new relations with the contents, deepen their knowledge, understand the concepts and reshape some of the previously acquired information.

The consolidation of learning relies on the completion by the students of various activities, including the use of computational simulation and data processing applications obtained from remote access labs, as well as answering questionnaires, problem solving, forums participation and elaboration of synthesis texts. Three other cognitive domains are explored with the performance of the various types of activities:

- Implementation, corresponding to the use of abstract representation in concrete and specific cases. The use of simulation tools, the remote access labs and problem solving are clear examples of the tasks framed in this cognitive domain;

- The analysis capacity (separating elements and establishing hierarchies and relations) is explored through the activities that involve decomposition and recombination of information and knowledge. Data processing, either collected from labs via remote control access or supplied in the framework of problem solving, or the application of analytical models for adjusting time evolutions obtained through monitoring processes, are good examples of the exploitation of this cognitive domain;

- The synthesis capacity (elements and separate parts merging to form a whole), is developed by tasks that aim to induce the original construction of new contents in a coherent way. The required texts, as result of the students reflexion process or as reports of activities, are framed in this cognitive domain. 
The students learning activities are carried out in accordance to the schedule defined and publicised at the beginning of the course. The period for delivering reports, the answers to questionnaires and the participation in discussion forums are clearly defined. The feedback to students on their performance in the various activities is given by the teaching staff via the Moodle platform. There is an improvement period at the end of each of the modules in which the students may submit new versions of some of the activities, in view of the comments and indications formulated by the teaching team members. The knowledge assessment tests are excluded from this possibility.

The importance of discussion forums is outlined in [6]. The forums are also used as communication tool between the various players in the course. A general forum is present in the entire length of the course, where students may discuss general themes within the course context, launch discussions, share experiences and post general questions. As stated in [6], 'online discussion fora are a valuable component for every e-learning System', enhancing the communication between the learners. Within the IECB course there is a particular forum for each module, where specific questions and doubts should be addressed.

Two examples of the virtual labs used in the context of the course are presented in Figure 3. The first application is a Microsoft Excel spreadsheet, previously developed to support lectures on Thermal Comfort contents [1]. In the context of this course, it is used for a training exercise to be developed by the students. A sensitivity analysis on the thermal comfort indices - PMV and PPD - and the several input parameters for the calculation are included in this work. The main objective of this exercise is that students acquire sensitivity for the relative and absolute effects on the thermal comfort sensation of both the environmental parameters (air temperature, mean radiant temperature, air velocity and partial vapour pressure) and the individual parameters (metabolic activity rate and clothing thermal insulation). It also allows students to realise the relative distribution of heat loss in the human body. The result of this analysis is required in the form of a conference paper in order to develop the student capacities of data analysis and information synthesis.

The other computational tool [7], developed in LabView, uses a finite difference solution of the differential equation that models the distribution over time of a pollutant concentration in a unizone indoor space. In this case, it simulates the evolution of the concentration of metabolic $\mathrm{CO}_{2}$, in function of the various parameters, namely, the volume of the space, the presence/absence of occupants, the occupants metabolic rate and body mass, the fresh air flow rate, the initial concentration of the pollutant and its concentration on the outside air.

This tool is used in one of the webinars in Module 2, which focuses on the evolution over time of a pollutant concentration. As it is possible to generate a movie showing how the pollutant concentration evolves as a function of the input parameter variation, this provides an interesting way of explaining the analytical method used for modelling these phenomena, contributing decisively towards a better understanding by the students. 


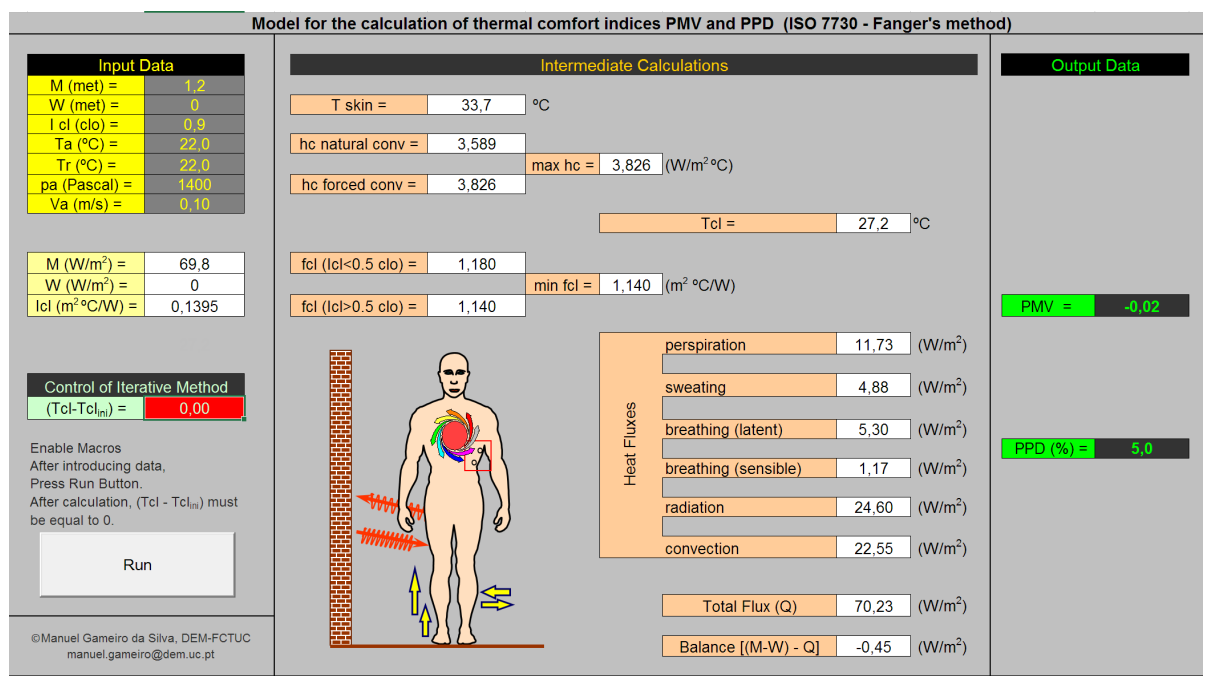

a)

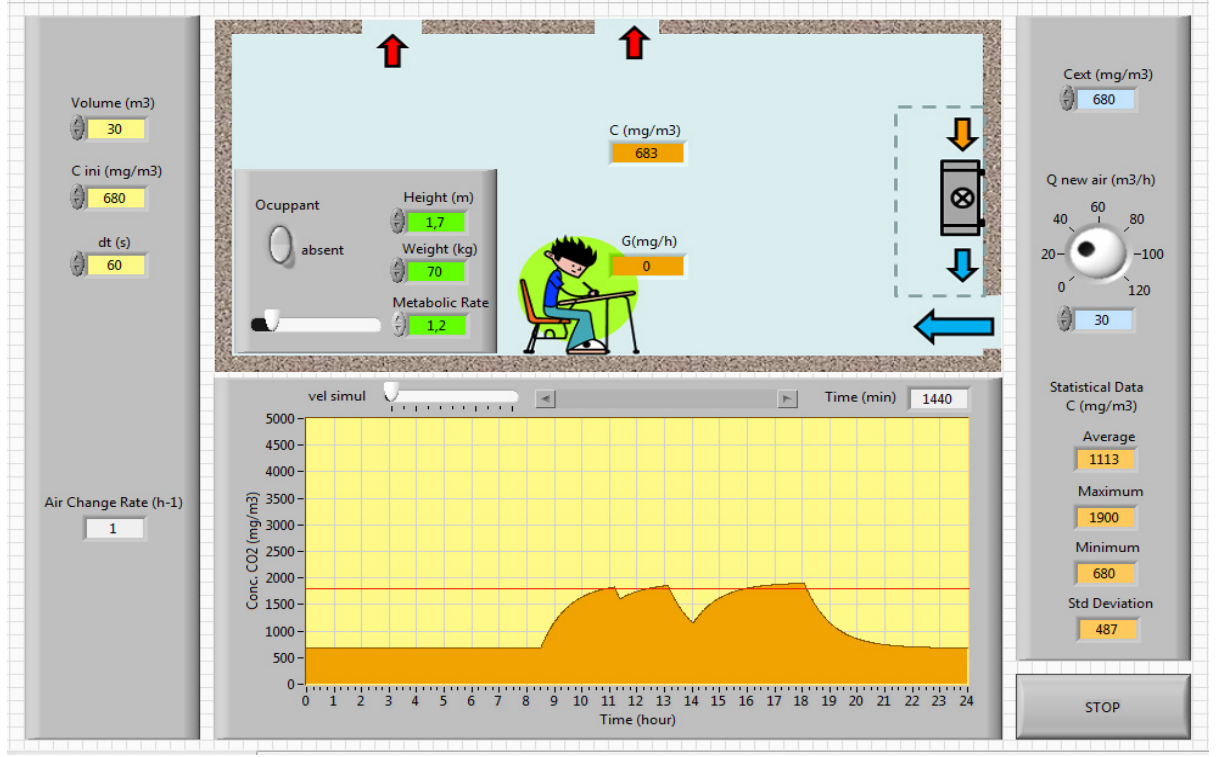

b)

Fig. 3. Examples of virtual labs used in the learning activities

a) Computational application for thermal comfort indices calculation (Activity 1.2 of Module 1 )

b) Virtual lab for time evolution simulation of a pollutant used in a Webinar in Module 2 
In Figure 4 are presented examples of two activities performed in Modules 3 and 4. As stated in [8], remote labs are receiving increasing attention. Moreover, these 'may play a relevant role complementing theory and practice' [9]. Herein, the first activity, presented in Figure 4.a, is a remote access lab, in which a real time environmental noise monitoring system is used [10], [11], [12]. This system is based on a virtual instrument application developed in LabView, for signal acquisition from a precision microphone through a National Instruments setup. Data post-processing allows the calculation of environmental noise descriptors and their evolution over time. Data display is done in Java Script putting together the measured data and real-time images of a webcam showing road traffic.

Through the provision on a website of the time evolution of the noise equivalent level simultaneously with real time images of the road traffic intensity in the zone, student understanding of the connection between these two variables is promoted. The students task, after visioning the remote access lab dynamic content, consists in processing data from one complete day, calculating the equivalent noise levels for different periods of the day (morning, evening, night), using the files available for download in the website.

In the activity referred in Figure 4.b, a file is provided with the results of a measuring campaign of the illuminance level in a workplace, containing data collected with a lux meter in a $2.5 \times 2.5 \mathrm{~cm}$ square mesh. Based on this information, students are asked to calculate the average illuminance indicators in the workplace, in agreement with the corresponding standard, and to discuss the sampling spatial magnitude effect on the uncertainty level of the obtained descriptors corresponding to the average illuminance and uniformity.

\section{Conclusions}

The methodology followed for designing and implementing a distance-learning course on Indoor Environmental Comfort in Buildings was presented. One of the main challenges faced by the members of the teaching team was guaranteeing that the strategies used in the learning/teaching tasks enabled a strong interaction between the students and their participative involvement, given the fact that the course was entirely run in a distance-teaching mode. The existence of some previously developed tools and the nature of the subjects under study enabled to achieve this challenge successfully. The challenges that the students have to face in the different activities enabled their learning progress based on their own work. The help towards a better understanding of the subjects provided by different support resources was positively acknowledged in the assessment of the course 1st edition. One particular issue was the positive role of the webinars as complement to the subjects/contents presentation. 


\section{Real Time Environmental Noise Monitoring}

ADAI, University of Coimbra, Portugal

18 March 2014 - download
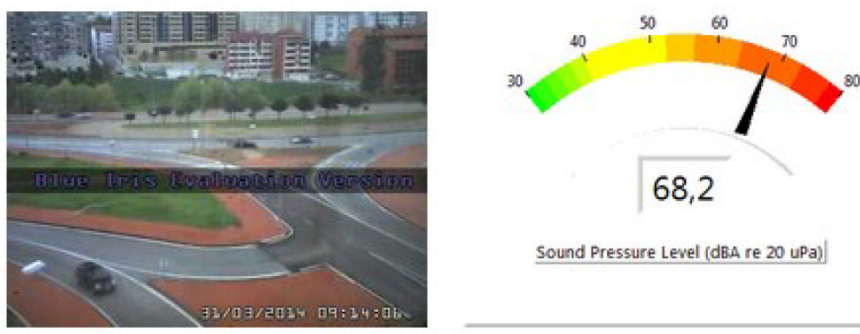

Sound Pressure Level (dBA re 20 upa)

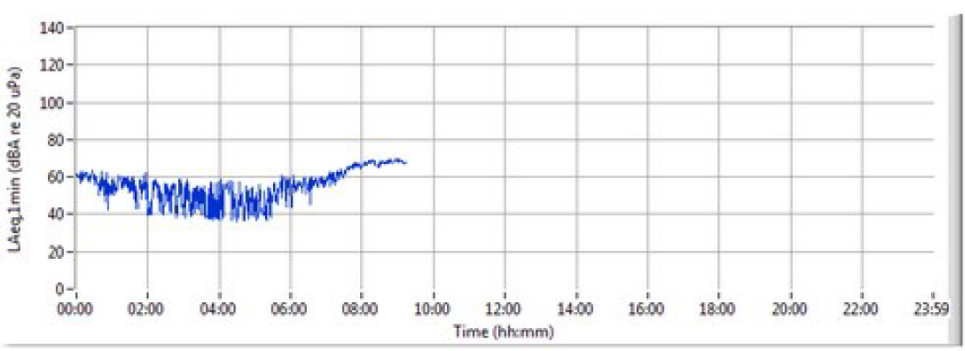

a)

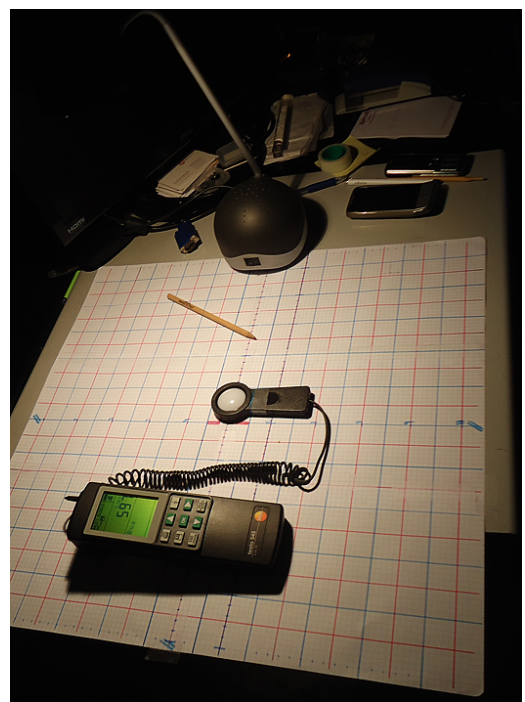

$600-700$

$500-600$

$\square 400-500$

$\square 300-400$

$\square$ 200-300

=100-200

- 0-100

(1)
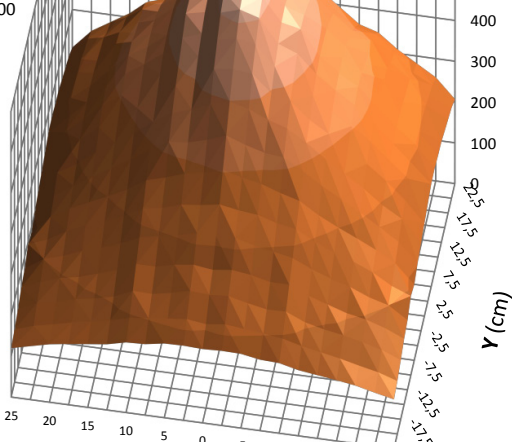

$\mathbf{X}(\mathrm{cm})$

b)

Fig. 4. Examples of activities used in the learning activities.

a) Remote Access Lab used in Module 3 (Noise and Vibration)

b) Analysis of data of a illuminance measuring campaign (Module 4 - Lighting) 


\section{Acknowledgement}

The paper has been prepared in the framework of the project TRAPHIC (ref. POCI-01-0145-FEDER-016729 and PTDC/ECM-URB/3329/2014).

\section{References}

[1] M. C. Gameiro da Silva, "Virtual Laboratories for a Course about Indoor Environmental Quality,” Spec. Issue Int. J. Emerg. Technol. Learn., vol. November, 2009.

[2] S. A. Batterman, A. G. Martins, C. H. Antunes, F. Freire, and M. Gameiro da Silva, "Development and Application of Competencies for Graduate Programs in Energy and Sustainability,” J. Prof. Issues Eng. Educ. Pract., vol. 137, no. 4, pp. 198-207, 2011. https://doi.org/10.1061/(ASCE)EI.1943-5541.0000069

[3] S. P. Corgnati, M. Gameiro da Silva, R. Ansaldi, E. Asadi, J. J. Costa, M. Filippi, J. Kaczmarcczyk, A. K. Melikov, B. W. Olesen, Z. Popiolek, and P. Wargocki, REHVA - Indoor Climate Quality Assessment, Guidebook no14. REHVA, 2011, 2011.

[4] "E-learning course: Indoor Environmental Comfort in Buildings (In Portuguese)," 2015. [Online]. Available: http://www.ed.uc.pt/educ/curso?id=64\&rea=1. [Accessed: 14-Sep2015].

[5] S. Pedrosa, J. Neto, A. Mendes, T. Pessoa, and M. Marcelino, "Concepção e desenvolvimento de cursos online - estratégias instrutivas utilizadas no ED.UC (In Portuguese)," in Actas do ICEM-SIIE Joint Conference 2011, 2011.

[6] F. Abel, I. I. Bittencourt, E. Costa, N. Henze, D. Krause, and J. Vassileva, "Recommendations in Online Discussion Forums for E-Learning Systems," IEEE Trans. Learn. Technol., vol. 3, no. 2, pp. 165-176, 2010. https://doi.org/10.1109/TLT.2009.40

[7] M. C. Gameiro da Silva, "Indoor Air Quality Simulation Tools," Rehva J. - Eur. J. Heating, Vent. Air-Conditioning Technol., vol. 46, no. 4, pp. 30-32, 2009.

[8] L. F. Gomes and J. García Zubía, Advances on remote laboratories and e-learning experiences, vol. 6. Bilbao: University of Deusto, 2007.

[9] Susana Romero, M. Guenaga, J. García-Zubía, and P. Orduña, "New challenges in the Bologna Process using Remote Laboratories and Learning Analytics to support teachers in continuous assessment," in International Symposium on Computers in Education (SIIE), 2014.

[10] M. Mateus and M. Gameiro da Silva, "Desenvolvimento de um sistema de monitorização contínua de ruído sobre uma plataforma LabVIEW," in Acústica 2012 - VIII Congresso Ibero-Americano de Acústica, 2012.

[11] J. Dias Carrilho, M. Mateus, and M. Gameiro da Silva, "Real time web publishing of environmental noise monitoring data, " accepted for presentation at the 3rd Experiment@ International Conference.

[12] M. Teresa Restivo and M. Gameiro da Silva, "Portuguese Universities Sharing Remote Laboratories,” Spec. Issue Int. J. Emerg. Technol. Learn., vol. November, 2009. 


\section{$7 \quad$ Authors}

Manuel Gameiro da Silva (corresponding author) is Associate Professor in Department of Mechanical Engineering of the University of Coimbra. He is the Coordinator of the Research Group in Energy, Environment and Comfort of ADAI-LAETA and the President of the Direction Board of the Portuguese Society of Engineering Education.

Luísa Dias Pereira holds a PhD in Sustainable Energy Systems from the University of Coimbra (UC) in the framework of the MIT-Portugal program. Her research is mainly focused on IAQ, Thermal Comfort and Energy Efficiency.

João A. Dias Carrilho holds a MSc in Engineering Acoustics and Vibration at the University of Southampton (2001). He has participated in several research projects in the field of IEQ and he is the main author of several scientific papers on this field. He is currently finishing is $\mathrm{PhD}$ in Sustainable Energy Systems.

Joana Neto is member of the pedagogical team of the UC_D (Special project of Distance Learning of the University of Coimbra). She holds a MSc in Pedagogical Sciences and she has authorship of scientific and conference papers.

Maria José Marcelino is an Assistant Professor at the Computer Science Department at the UC, and she is member of the Scientific /Pedagogical coordination of the UC_D (Special project of Distance Learning of the University of Coimbra).

Mário Mateus is an Electrical Engineer who further developed his studies on Mechanical Engineering -both MSc and $\mathrm{PhD}$ : "The influence of the parameters pf sampling in the uncertainty of environmental noise". He is an author of several scientific papers, mainly in the field of Acoustics and he is Professor at DEM- UC.

Nelson Brito is an architect. He was an invited Professor at the University of Minho, Portugal (2009-12) and he is currently finishing is Ph.D. on "Upgrade opportunities for buildings in city centers".

Sandra Pedrosa is member of the pedagogical team of the UC_D (Special project of Distance Learning of the University of Coimbra). She holds a MSc in Pedagogical Sciences and she has authorship of scientific and conference papers.

Article submitted 22 November 2016. Published as resubmitted by the authors 13 February 2017. 